\title{
Evolution of microstructure in advanced ferritic-martensitic steels under irradiation: the origin of low temperature radiation embrittlement
}

\author{
S. Rogozhkin ${ }^{1,2}$, A. Nikitin ${ }^{1,2}$, N. Orlov ${ }^{1,2}$, A. Bogachev ${ }^{1,2}$, O. Korchuganova ${ }^{1,2}$, A. Aleev ${ }^{1,2}$, \\ A. Zaluzhnyi ${ }^{1,2}$, T. Kulevoy ${ }^{1,2}$, R. Lindau ${ }^{3}$, A. Möslang ${ }^{3}$, P. Vladimirov ${ }^{3}$ \\ ${ }^{1}$ State Scientific Centre of the Russian Federation - Institute for Theoretical and Experimental \\ Physics of National Research Centre "Kurchatov Institute”, 117218 Moscow, Russia \\ ${ }^{2}$ National Research Nuclear University “MEPhI”, 115409 Moscow, Russia \\ ${ }^{3}$ Karlsruhe Institute of Technology, 76344 Karlsruhe, Germany
}

\begin{abstract}
Advanced reduced activation ferritic/martensitic steels and oxide dispersion-strengthened steels exhibit significant radiation embrittlement under low temperature neutron irradiation. In this study we focused on atom probe tomography (APT) of Eurofer97 and ODS Eurofer steels irradiated with neutrons and heavy ions at low temperatures. Previous TEM studies revealed dislocation loops in the neutron-irradiated flm steels. At the same time, our APT showed early stages of solid solution decomposition. High density $\left(10^{24} \mathrm{~m}^{-3}\right)$ of $\sim 3-5 \mathrm{~nm}$ clusters enriched in chromium, manganese, and silicon atoms were found in Eurofer 97 irradiated in BOR-60 reactor to $32 \mathrm{dpa}$ at $332^{\circ} \mathrm{C}$. In this steel irradiated with Fe ions up to the dose of $24 \mathrm{dpa}$, pair correlation functions calculated using APT data showed the presence of Cr-enriched pre-phases.

APT study of ODS Eurofer found a significant change in the nanocluster composition after neutron irradiation to $32 \mathrm{dpa}$ at $330{ }^{\circ} \mathrm{C}$ and an increase in cluster number density. APT of ODS steels irradiated with Fe ions at low temperatures revealed similar changes in nanoclusters.

These results suggest that irradiation-induced nucleation and evolution of very small precipitates may be the origin of low temperature radiation embrittlement of $\mathrm{f} \backslash \mathrm{m}$ steels.
\end{abstract}

\section{INTRODUCTION}

Reduced activation ferritic/martensitic (RAFM) steels and oxide dispersion strengthened RAFM steels are considered as promising structural materials for future fusion and fission reactors with extreme operational conditions at high neutron fluxes $\left(\sim 10^{13}-10^{14} \mathrm{n} / \mathrm{cm}^{2} \mathrm{~s}\right)$ and at elevated temperatures (up to $700^{\circ} \mathrm{C}$ ) . Eurofer97 steel is targeted to be used as structural material for ITER blanket test units and in future versions of fusion reactors [1]. Mechanically alloyed oxide dispersion strengthened ODS Eurofer steel was developed on the base of Eurofer 97 steel to increase creep-rupture resistance [1-2]. ODS Eurofer steel contains numerous nanosized $\mathrm{Y}_{2} \mathrm{O}_{3}$ particles (partly coherent with the matrix), which are formed directly after hot isostatic pressing of this material [3-4]. APT study of the initial state of this material has revealed a large number $\left(\sim 2 \times 10^{24} \mathrm{~m}^{-3}\right)$ of ultrafine nanosized (1-4 nm) clusters enriched in $\mathrm{Y}, \mathrm{O}$ as well as $\mathrm{V}, \mathrm{N}$ [5]. These dispersed oxide inclusions provide extremely high temperature resistance to ODS steels.

Extensive studies of the properties of these materials have been carried out [6-11]. The most complicated problem is to investigate their radiation resistance, especially at high displacement damage doses. Specimens of the Eurofer97 irradiated in High Flux Reactor (HFR, Petten, Netherlands) to doses of 2.5, 8.4, and 16.3 dpa have been studied in [12-15]. The effect of irradiation up to 32 dpa has been analyzed in a BOR 60 reactor (Dimitrovgrad) in the framework of ARBOR 1 project $[8,16]$. The next was ARBOR 2 project, which involved an 
increase in the irradiation dose to $70 \mathrm{dpa}$ [17]. The study of the irradiated specimens demonstrated degradation of the mechanical properties under neutron irradiation, i.e., radiation strengthening and therefore the loss of ductility. Irradiation of Eurofer 97 at temperatures of $300-335^{\circ} \mathrm{C}$ to $70 \mathrm{dpa}$ resulted in a ductile to brittle transition temperature (DBTT) shift of more than $200^{\circ} \mathrm{C}$. Specimens of ODS Eurofer steels were irradiated in HFR reactor to the doses of 1 and 3 dpa [18], in High Flux Isotope Reactor (HFIR) at ORNL to 1.5 dpa [19], in the Belgian Reactor 2 (BR2) in Mol up to of 1.73 dpa [20]. In Arbor 1 and 2 projects ODS Eurofer was irradiated up to 32 [8] and 40 dpa [9], correspondingly. The embrittlement ODS Eurofer was higher than that of Eurofer 97. Irradiation of ODS Eurofer at $332{ }^{\circ} \mathrm{C}$ to 32 dpa resulted in the DBTT shift of $247^{\circ} \mathrm{C}$, irradiation at $325^{\circ} \mathrm{C}$ to 40 dpa resulted in a the DBTT shift of $\sim 350{ }^{\circ} \mathrm{C}$, and after irradiation to 69 dpa, ODS Eurofer completely lost ductility [9].

All the mentioned ferritic-martensitic steels showed a large increase in the ductile to brittle transition temperature under irradiation at $\sim 30{ }^{\circ} \mathrm{C}$ in the dose range of about a few dpa. TEM-visible irradiation microstructural reconstruction does not explain the observed hardening of irradiated Eurofer 97 [21]. The low temperature radiation embrittlement of ODS Eurofer steel is considerably higher than Eurofer 97, and the embrittlement origin is worse understood.

The purpose of this article is to provide an analysis of the microscopic origin of mechanical properties degradation of Eurofer 97 and ODS Eurofer steels under low temperature irradiation.

\section{MATERIALS}

An industrial batch of European RAFM steel Eurofer97 was produced by Böhler Austria $\mathrm{GmbH}$. ODS Eurofer samples were produced at Plansee by mechanical alloying of Eurofer powder with $0.5 \%$ yttria. After consolidation by hot isostatic pressing, the bar was normalized at $1100{ }^{\circ} \mathrm{C}$ for $30 \mathrm{~min}$ followed by an air/ water quench and then tempered at $750{ }^{\circ} \mathrm{C}$ for $2 \mathrm{~h}$. To obtain a well-defined martensitic-ferritic structure, the investigated materials were finally subjected to a two-step heat treatment at about $980{ }^{\circ} \mathrm{C} / 30 \mathrm{~min}$, followed by $760{ }^{\circ} \mathrm{C} / 2 \mathrm{~h}$.

The compositions of Eurofer97 and ODS Eurofer steels are indicated in table I. Specimens from these steels were irradiated by neutrons in the BOR 60 in the framework of the ARBOR 1 project [8] to displacement damage dose of $\sim 32 \mathrm{dpa}$ at $330^{\circ} \mathrm{C}$. The fast neutron flux was equal to 1.8 $\times 10^{19} \mathrm{n} / \mathrm{m}^{2} \mathrm{~s}(>0.1 \mathrm{MeV})$. Irradiated specimens for atom probe tomography (APT) were cut from the parts of broken Charpy impact test samples. The test temperatures of irradiated Eurofer 97 and ODS Eurofer were $200{ }^{\circ} \mathrm{C}$ and $330^{\circ} \mathrm{C}$ respectively.

Table I. The chemical composition of Eurofer 97 and ODS Eurofer, wt. \%.

\begin{tabular}{|c|c|c|c|c|c|c|c|c|c|}
\hline Material & $\mathrm{C}$ & $\mathrm{Si}$ & $\mathrm{Mn}$ & $\mathrm{Cr}$ & $\mathrm{N}$ & $\mathrm{V}$ & $\mathrm{W}$ & $\mathrm{Ta}$ & $\mathrm{Y}_{2} \mathrm{O}_{3}$ \\
\hline Eurofer 97 & 0.11 & 0.08 & 0.37 & 8.94 & 0.027 & 0.19 & 1.07 & 0.87 & - \\
\hline ODS Eurofer & 0.11 & 0.079 & 0.37 & 8.98 & 0.007 & 0.19 & 1.09 & 0.87 & 0.50 \\
\hline
\end{tabular}

Nanoscale reconstruction of ferritic-martensitic steels under heavy ion irradiation was also studied with heavy ion irradiation [22, 23]. Atom probe specimens with an apex radius of $50 \mathrm{~nm}$ were used for the irradiation experiment. The scheme of the irradiation was described in 
$[23,24]$. The irradiation was performed using a pulsed ion beam from the Metal Vapor Vacuum Arc (MEVVA) ion source (IS) with an energy of $75 \mathrm{keV} / \mathrm{Z}$ (where $\mathrm{Z}$ is the ion charge), the pulse duration of $450 \mu \mathrm{s}$, and the pulse repetition rate of less than $0.25 \mathrm{~Hz}$ under a vacuum of greater than $2 \times 10^{-6} \mathrm{mbar}$ [25]. The beam current provided by IS was equal to $200 \mathrm{~mA}$. The current density measured on the target reached $5-6 \mathrm{~mA} / \mathrm{cm}^{2}$. The irradiation was performed with Fe ion beam consisted of three different types of ions (characteristic of the MEVVA source), i.e., $\mathrm{Fe}^{+}(25 \%), \mathrm{Fe}^{2+}(68 \%)$, and $\mathrm{Fe}^{3+}(7 \%)$ with energies of 75, 150, and $225 \mathrm{keV}$, respectively. This beam creates a maximum number of defects at the depth of $\sim 30-50 \mathrm{~nm}$, which corresponds to the middle of the needle sample. According to the SRIM calculations, the maximum number of the generated defects in pure Fe under Fe ion MEVVA irradiation is located at about $40 \mathrm{~nm}$ depth (figure 1).

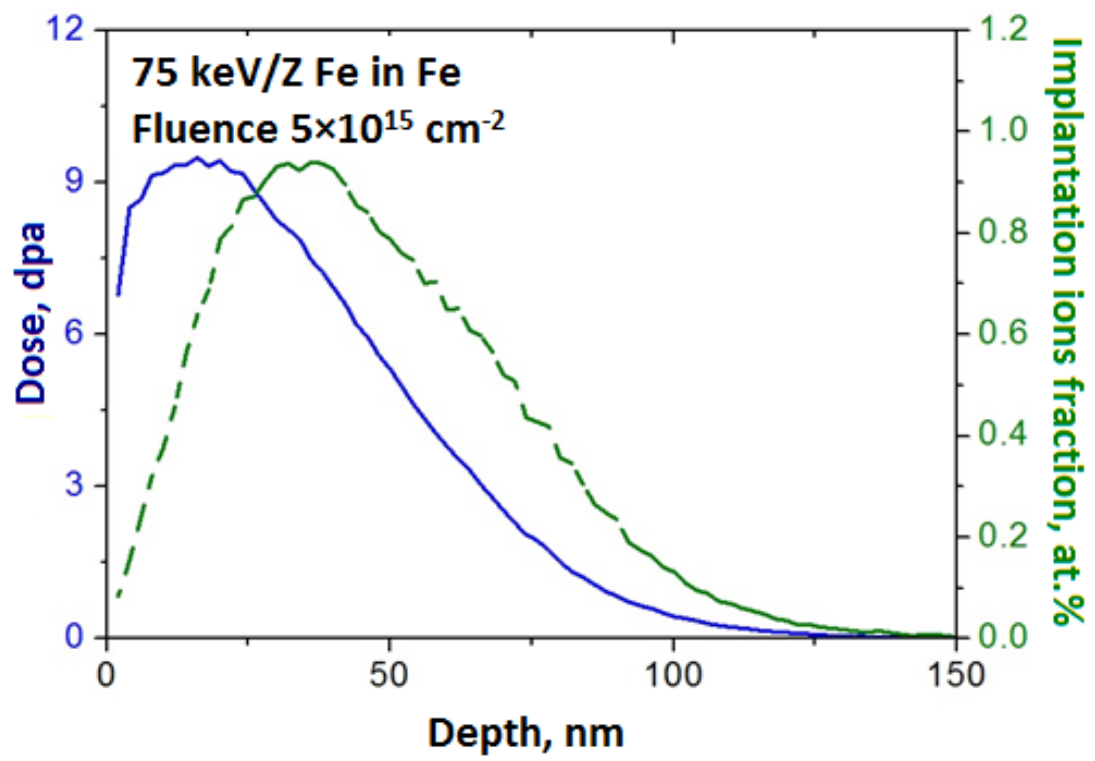

Figure 1. The SRIM damage profile (blue solid line) and ion implantation profile (green dashed line) for pure Fe irradiated by $75 \mathrm{keV} / \mathrm{Z}$ Fe beam from MEVVA ion source. The calculations were carried out for the dose of $5 \times 10^{15} \mathrm{~cm}^{-2}$, using the threshold displacement energy of $40 \mathrm{eV}$ and the Kinchin-Pease option.

\section{EXPERIMENT}

The APT samples of Eurofer 97 and ODS Eurofer steels were studied with an Energy Compensated Optical Tomographic Atom Probe (ECOTAP). Atom probe data acquisition was performed under ultrahigh vacuum at $40-80 \mathrm{~K}$. The pulse repetition rate had the maximum value of $1.6 \mathrm{kHz}$. The pulse fraction was within $15-23 \%$ and was adjusted to the specimen temperature for better performance.

The mass resolution measured as ratio of the position of the peak in mass-to-charge units to its full width at half maximum intensity $\left(\mathrm{M} / \Delta \mathrm{M}_{50 \%}\right)$ was greater than 700 , whereas for some peaks even the value of 1200 was reached. The dependence of pulse evaporation efficiency on 
pulse fraction and specimen temperature for Cr was analysed. Within the parameter range used, other elements were not affected. The optimal values were determined at $70 \mathrm{~K}$ and $19 \%$ pulse fraction. However, some data for ODS Eurofer were obtained at $80 \mathrm{~K}$ and $9 \%$ pulse fraction and for Eurofer 97 at $70 \mathrm{~K}$ and $15 \%$ pulse fraction. That only influenced the average $\mathrm{Cr}$ concentration observed in the acquired volumes.

The data processing included the analysis of obtained mass spectrum and the reconstruction of spatial distribution of chemical elements in the studied volume. To analyze the material features, the maximum separation method was used [26]. The parameters of cluster analysis such as the maximum separation distance $d_{\max }$ between atoms in a cluster and the minimum number of atoms $N_{\min }$ to be considered as a cluster were chosen for different materials separately. An additional analysis of the material inhomogeneity was carried out with pair correlation (PCF) and frequency distribution functions [26].

\section{RESULTS}

\section{APT study of irradiated samples of Eurofer 97}

No chemical element segregations were found in non-irradiated Eurofer 97 steels. All the elements were uniformly distributed in the investigated volumes. Some deviation of the composition observed by ECOTAP was found [11]. This could be the result of segregation or formation of different precipitates (e.g. $\mathrm{M}_{23} \mathrm{C}_{6}$ complex carbides).

Figure 2 shows the examples of the 3D reconstruction of atom probe data for a neutron irradiated Eurofer 97 specimen. The diffuse areas enriched with $\mathrm{Cr}$ atoms can be seen in the atom map. The maximum separation method was used to detect and evaluate areas with increased concentrations of $\mathrm{Cr}, \mathrm{Si}$, and $\mathrm{Mn}$ in Eurofer97 samples. The parameters used for cluster identification were $d_{\max }=1 \mathrm{~nm}$ and number of $\mathrm{Cr}$, Si and $\mathrm{Mn}$ atoms $\mathrm{N}_{\min }=13$. The estimated size, number density and chemical composition of these precipitates are shown in table II. Chromium is the main alloying element in these areas. They are enriched in this chemical element by 5 to 20 at.\% in comparison to the matrix. Moreover, these precipitates are highly enriched in manganese (up to $4 \pm 1$ at.\%) and silicon (up to $0.4 \pm 0.1$ at.\%).

\section{$10 \mathrm{~nm}$}

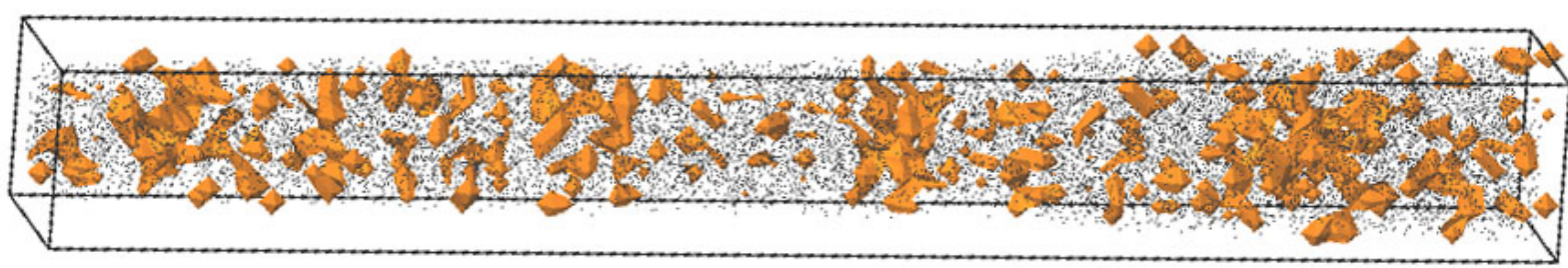

Figure 2. 3D reconstruction of a volume of neutron irradiated Eurofer 97. Isosurface of 20 at.\% Cr showing $\mathrm{Cr}$ precipitates $(\bullet)$ in Fe matrix $(\bullet)$. 
Table II. Average size and number density of the nanoscale clusters observed in irradiated Eurofer 97 specimens.

\begin{tabular}{|l|c|c|c|}
\hline \multirow{2}{*}{ Material } & \multicolumn{2}{|c|}{ Neutron irradiated } & Ion irradiated \\
\cline { 2 - 4 } & $\begin{array}{c}\text { Average size, } \mathrm{nm} \\
\text { cluster analysis } \\
\text { (correlation analysis) }\end{array}$ & $\begin{array}{c}\text { Number density, } \\
\mathrm{m}^{-3}\end{array}$ & $\begin{array}{c}\text { Average size, } \mathrm{nm} \text {; } \\
\text { cluster analysis } \\
\text { (correlation analysis) }\end{array}$ \\
\hline Eurofer97 & $2,6 \pm 0,8(3,7 \pm 0,4)$ & $\sim 5 \times 10^{24}$ & $(1,5-3)$ \\
\hline ODS Eurofer & $1-5$ & $\sim 4 \times 10^{24}$ & $2-4$ \\
\hline
\end{tabular}

Since these areas with increased concentrations of the alloying elements are diffuse, their analysis is a complicated task. Additional estimation of the average sizes of the precipitates was carried out using the approach based on pair correlation functions analysis [26, 11]. Figure 3 shows the pair correlation functions $G_{\mathrm{CrCr}}$ for the Eurofer97 irradiated in the BOR 60 reactor up to $32 \mathrm{dpa}$. The spherical layer used to plot the correlation function is $0.2 \mathrm{~nm}$ thick.

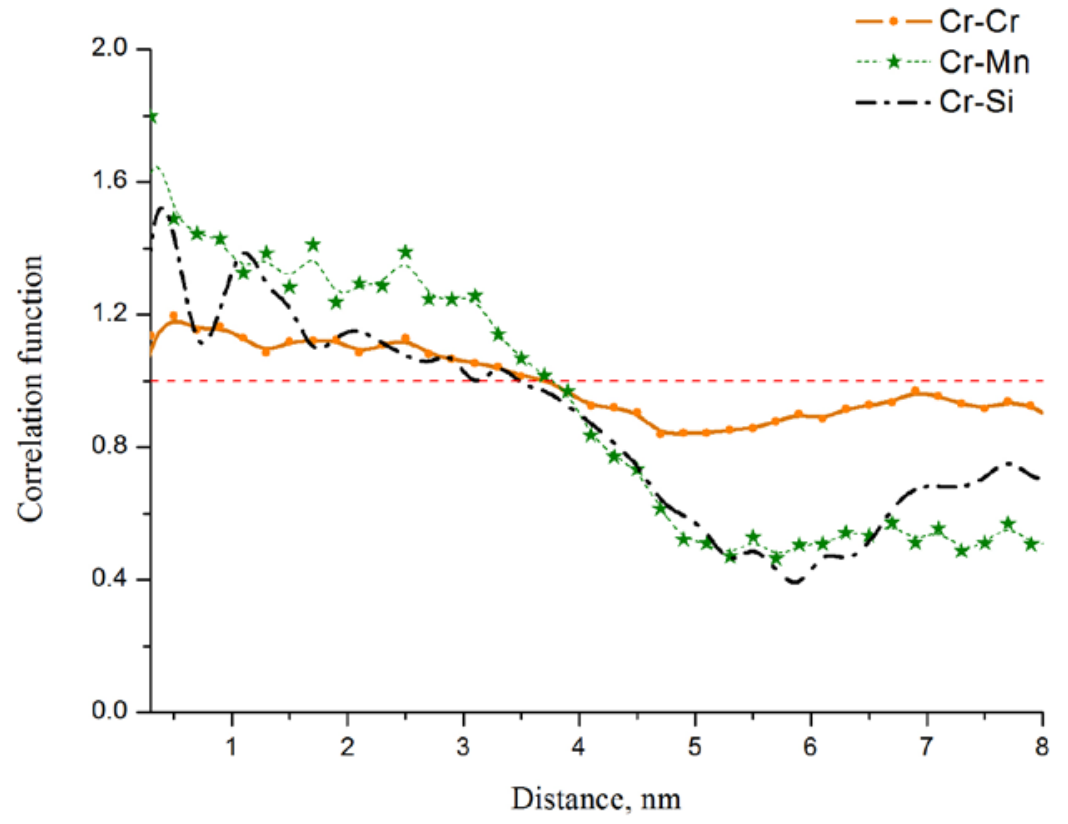

Figure 3. Pair correlation functions $G_{\mathrm{CrCr}}, G_{\mathrm{CrMn}}$ and $G_{\mathrm{CrSi}}$ for Eurofer 97 steel irradiated with neutrons to $32 \mathrm{dpa}$ at $330{ }^{\circ} \mathrm{C}$. Line $G=1$ refers to homogeneous solid solution.

A comparison between the PCFs for the original Eurofer97 material and for the model solid solution has shown that chromium atoms are practically uniformly distributed in the unirradiated metal. A pronounced correlation between the chromium atoms is observed in the irradiated material, which is indicative of the presence of precipitates. To analyze the distribution of the chemical elements in the volume of the irradiated material, the correlation functions $G_{\mathrm{CrMn}}$ and $G_{\mathrm{CrSi}}$ were plotted (figure 3). The analysis of the functions shows a strong correlation between $\mathrm{Cr}$ and $\mathrm{Mn}$ atoms. The correlation between $\mathrm{Cr}$ and $\mathrm{Si}$ atoms is not considerable. Strong correlations between $\mathrm{Cr}$ and $\mathrm{Mn}$ atoms allow us to suppose that it is precisely their interaction that promotes the formation of the precipitation nuclei found. 


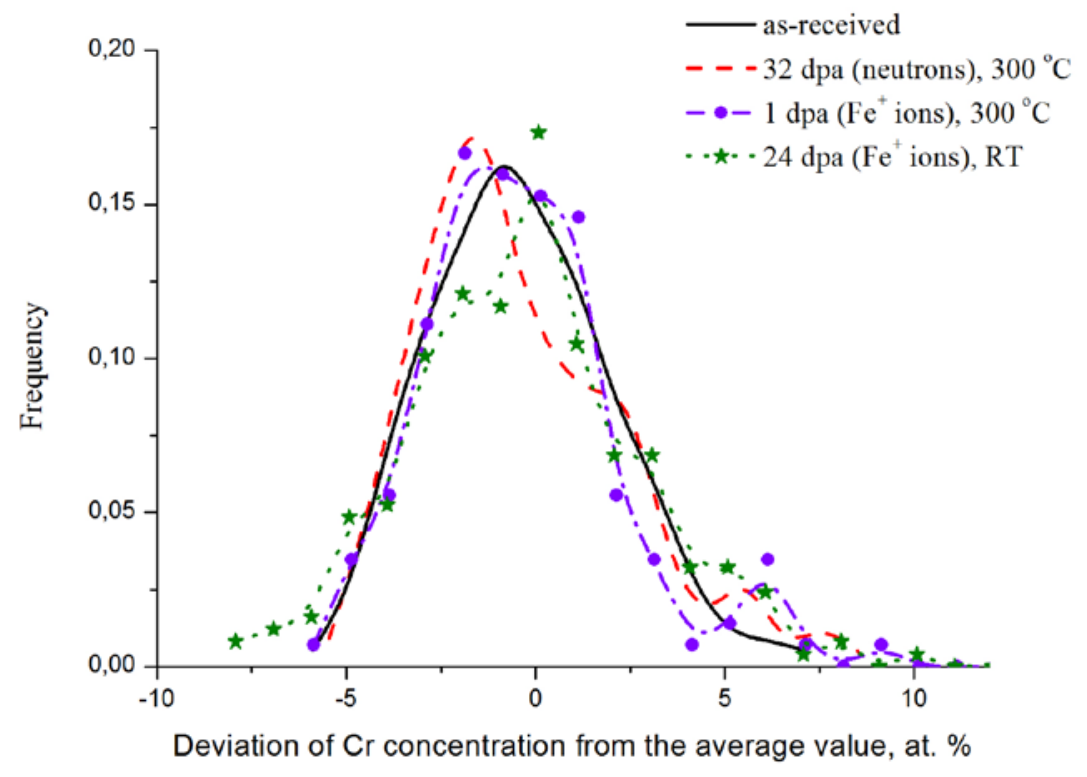

Figure 4. Frequency distribution of chromium in neutron and ion irradiated Eurofer 97 specimens.

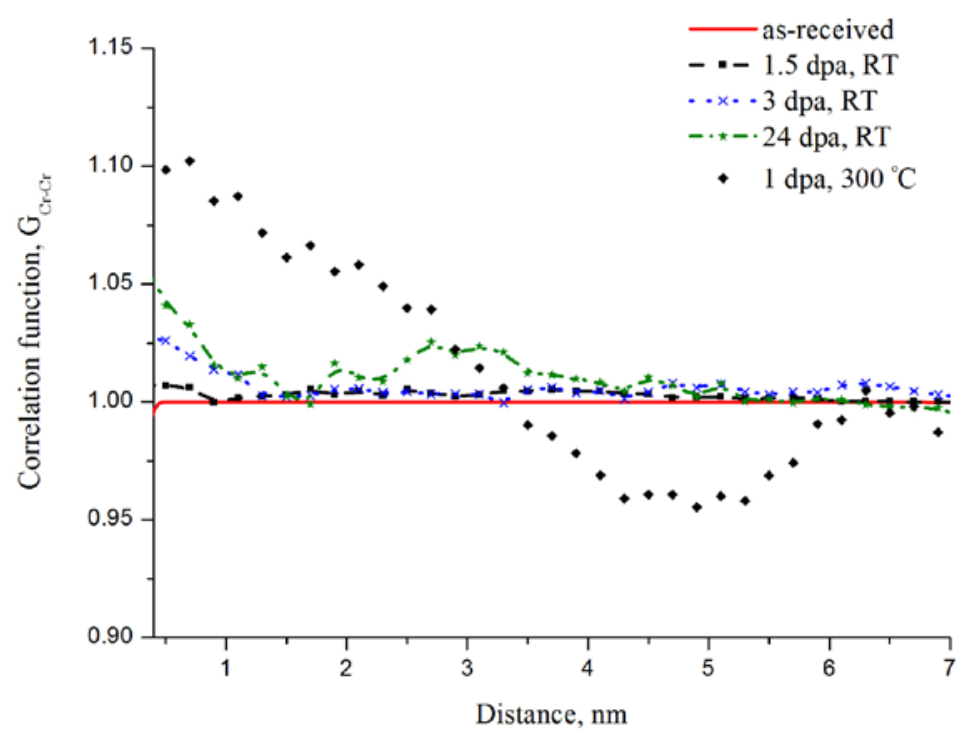

Figure 5. Pair correlation function $G_{\mathrm{CrCr}}$ for Fe ion irradiated Eurofer 97.

The pair correlation functions have allowed us to determine the average size of segregations of chromium atoms in the materials under study (table II). The estimated sizes were 3 to $4 \mathrm{~nm}$.

Eurofer 97 APT needles were irradiated with Fe ions up to $~ 20$ dpa at RT. The results of APT data processing are presented in figures 4 and 5 . Information about the solid solution in Eurofer 97 is presented as frequency distribution functions in figure 4. It shows solid solution 
decomposition and formation of chromium enriched and depleted regions after irradiation up to 24 dpa dose. The observed effect was more noticeable in the case of irradiation at $300{ }^{\circ} \mathrm{C}$.

The pair Cr-Cr correlation function for unirradiated Eurofer 97 is close to 1 that corresponds to homogeneous solid solution. This correlation for ion irradiated material grows up at small distances. According to the correlation function, some nucleation of small areas took place under irradiation up to $24 \mathrm{dpa}$ at RT. The average size of these segregations is $1.5 \mathrm{~nm}$. This value is rather less than that one after neutron irradiation (see table II). It can be caused by the lower dose and irradiation temperature.

The observed segregations cannot be related to the $\alpha$ ' phase found in high chromium steels and model alloys in $[27,28]$. However, they may be nuclei of the phases enriched in chromium, such as carbides and $\alpha$ ' phases.

An analysis of the chemical composition of the matrix of the neutron irradiated Eurofer 97 shows that it is up to 1.5 fold depleted in chromium. A decrease in the chromium concentration of in the solid solution caused by the carbides formation, in particular, due to heat treatments that result in the precipitation hardening of ferritic-martensitic steels.

\section{APT study of irradiated samples of ODS Eurofer}

The results of APT study of ODS Eurofer steel irradiated with neutrons to $32 \mathrm{dpa}$ at 330 ${ }^{\circ} \mathrm{C}$ are presented in figure 6 and tables III and IV. Unirradiated ODS Eurofer steel contains high number density clusters enriched in Y, O, V and N (figure 6A). From figure 6B it is easy to see that clusters in the neutron irradiated steel contains $\mathrm{Y}, \mathrm{O}$ and $\mathrm{Mn}$. The atom distribution analysis of the investigated volumes using the maximum separation method revealed areas enriched with $\mathrm{Y}, \mathrm{O}, \mathrm{Mn}, \mathrm{Cr}$ and slightly with $\mathrm{Si}$. The cluster identification procedure was carried out using parameters $d_{\max }=0.8 \mathrm{~nm}$ and $N_{\max }=5$ atoms. The typical cluster size varies from 1 to $5 \mathrm{~nm}$ with the average value of $3 \mathrm{~nm}$. The estimated number density of these clusters in the investigated volumes is about $4 \times 10^{24} \mathrm{~m}^{-3}$.

The element concentrations of observed clusters are presented in table III. The concentration of minor solutes in these clusters varies in a wide range while the elements like $\mathrm{Y}$, $\mathrm{O}, \mathrm{Si}$ and $\mathrm{Mn}$ are always presented. Moreover, their total concentration in Y-O clusters is within 6-9 at.\% and they are considerable enriched in Cr comparing to the matrix (table IV).

The data processing also revealed matrix enrichment in some other chemical elements under irradiation. The difference in their concentrations between APT data for un- and irradiated states (see table II) may be caused by radiation-induced dissolution of larger yttria particles $\left(\mathrm{Y}_{1.8} \mathrm{Mn}_{0.2}\right) \mathrm{O}_{3}$, which were previously detected by TEM in the unirradiated state [25].

Therefore, the study of ODS Eurofer samples neutron irradiated to $32 \mathrm{dpa}$ at $330{ }^{\circ} \mathrm{C}$ revealed changes in the composition of nanoclusters. As it was mention above, in the unirradiated steel, nanoclusters are enriched in Y, O, Cr, V and N. However, after neutron irradiation, the $\mathrm{V}$ and $\mathrm{N}$ concentrations in nanoclusters decreases, while the concentrations of $\mathrm{Y}$ and $\mathrm{Mn}$ increases.

To study the details of nanostructure evolution, APT samples of ODS Eurofer were irradiated with Fe ion beam in the range of doses up to $32 \mathrm{dpa}$ at RT. The results of APT characterization of ion irradiated samples are presented in tables III and IV. It can be seen that, as before, clusters enriched in $\mathrm{Y}$ and $\mathrm{O}$ are observed in the steel under Fe ion irradiation. At the same time, the irradiation leads to the partial removal of $\mathrm{N}$ and $\mathrm{V}$ from the clusters. In this case, 
sizes and number density of clusters do not change and remain in the range of $2-4 \mathrm{~nm}$ and $\sim 10^{24}$ $\mathrm{m}^{-3}$, respectively. To analyze the kinetics of changes in ODS Eurofer under irradiation, tables III and IV present the data for the initial state; the states after irradiation with Fe ions at RT to doses of $3,10,13$, and $32 \mathrm{dpa}$; and the data after neutron irradiation at $330^{\circ} \mathrm{C}$. A comparison of the concentrations of chemical elements in the matrix for different states (table IV) shows that, the bigger the irradiation dose is the more the contents of $\mathrm{V}, \mathrm{Mn}, \mathrm{O}$, and $\mathrm{Y}$ in the matrix are. This effect is partly caused by the radiation induced escape of some elements from the clusters. It should be mentioned that the concentrations of $\mathrm{Mn}, \mathrm{Y}$, and $\mathrm{O}$ averaged over the investigated volumes (whose sizes are $\sim 10 \times 10 \times 100 \mathrm{~nm}^{3}$ ) increased under ion irradiation. These changes cannot be explained by the redistribution of elements inside the investigated volumes (the exchange of elements between the clusters and the matrix). This increase appears to be caused by the dissolution of coarser oxide particles $\left(\mathrm{Y}_{1.8} \mathrm{Mn}_{0.2}\right) \mathrm{O}_{3}$, which have not been revealed by atom probe tomography due to their small number density.

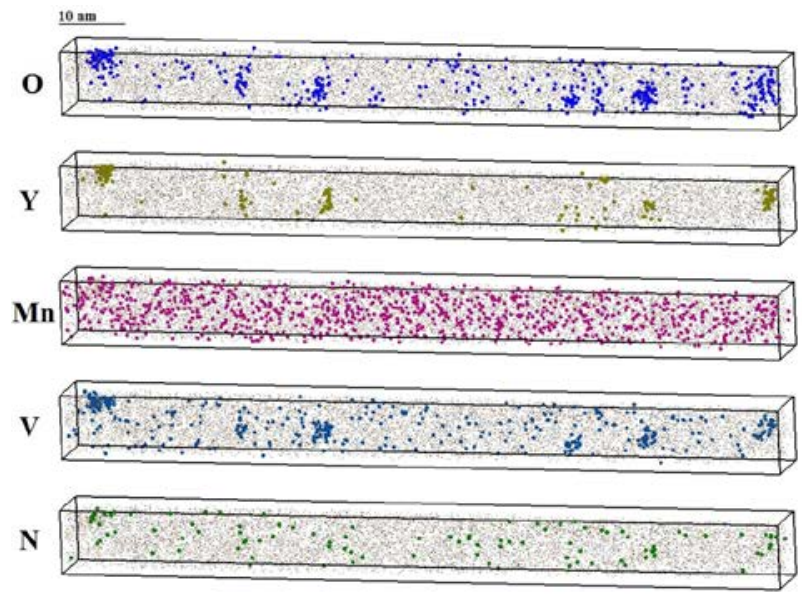

A

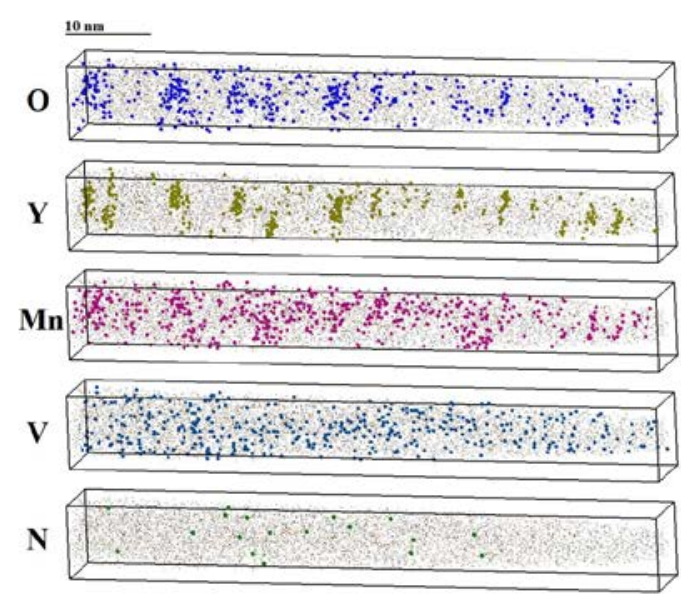

B

Figure 6. 3D reconstruction of volumes of unirradiated (A) and neutron irradiated (B) ODS Eurofer. O, Y, Mn, V, N atoms are represented. Small dots refer to matrix (Fe and Cr) atoms. Clusters enriched in $\mathrm{Y}, \mathrm{O}, \mathrm{V}$, and $\mathrm{N}$ are visible in the unirradiated steel and clusters enriched in $\mathrm{Y}, \mathrm{O}$ and $\mathrm{Mn}$ are visible in the neutron irradiated steel.

Table III presents the concentrations of chemical elements in clusters for different ion irradiated states. It can be seen that, when the damage dose increases, the concentrations of $\mathrm{V}$ and $\mathrm{N}$ in the clusters decrease, which is caused by the exchange of elements between the clusters and surrounding matrix under irradiation. The comparison of the clusters composition in the unirradiated state and after irradiation by ions and neutrons to the dose of $32 \mathrm{dpa}$ is shown in table III. The main changes in ODS Eurofer under ion irradiation are in good agreement with the effects observed after neutron irradiation: $\mathrm{V}$ and $\mathrm{N}$ escape from clusters into the surrounding matrix; the concentrations of $\mathrm{Y}, \mathrm{O}$, and $\mathrm{Mn}$ increase not only in the matrix around the clusters, but also on the whole in the investigated volumes. However, note that there is some discrepancy in the behavior of the concentrations of $\mathrm{Y}$ and $\mathrm{Mn}$ in the clusters under ion and neutron irradiation. Despite the increase in their concentrations in the matrix (table I) and on the whole in the investigated volumes, in clusters it is considerably smaller than under neutron irradiation. One of the possible reasons for this discrepancy may be that the temperature in the ion irradiation experiment was not high enough. In this case, the number density of clusters after irradiation is 
the same as in the initial state $(0.8 \pm 0.5) \times 10^{24} \mathrm{~m}^{-3}$. Note that, after neutron irradiation, the number density of clusters increases to $(2.4 \pm 1.0) \times 10^{24} \mathrm{~m}^{-3}$. The main processes of the exchange of the elements between the clusters and matrix (e.g., $\mathrm{V}$ and $\mathrm{N}$ ) are observed at doses $\leq 10$ dpa (tables II and IV). These doses correspond to the overlap of cascade regions in which the defects are predominantly generated under ion and neutron irradiation.

Table III. Average concentrations of chemical elements (at. \%) in clusters in ODS Eurofer steel in different states.

\begin{tabular}{|c|c|c|c|c|c|c|c|}
\hline at. \% & $\mathrm{Cr}$ & $\mathrm{Y}$ & $\mathrm{O}$ & $\mathrm{V}$ & $\mathrm{N}$ & $\mathrm{Mn}$ & $\mathrm{Si}$ \\
\hline Unirradiated state & $11.6 \pm 1.3$ & $1.6 \pm 0.5$ & $1.9 \pm 0.5$ & $2.5 \pm 0.6$ & $0.5 \pm 0.3$ & $0.4 \pm 0.2$ & $0.4 \pm 0.2$ \\
\hline $\begin{array}{c}\text { Fe ion irradiated to } \\
\text { 3 dpa }\end{array}$ & $10.7 \pm 1.3$ & $1.4 \pm 0.5$ & $1.5 \pm 0.5$ & $2.2 \pm 0.6$ & $0.3 \pm 0.2$ & $0.4 \pm 0.3$ & $0.4 \pm 0.2$ \\
\hline $\begin{array}{c}\text { Fe ion irradiated to } \\
\text { 10 dpa }\end{array}$ & $10.3 \pm 1.5$ & $2.3 \pm 0.7$ & $1.9 \pm 0.7$ & $1.2 \pm 0.5$ & $0.1 \pm 0.1$ & $0.5 \pm 0.3$ & $0.5 \pm 0.3$ \\
\hline $\begin{array}{c}\text { Fe ion irradiated to } \\
\text { 13 dpa }\end{array}$ & $9.7 \pm 1.4$ & $1.9 \pm 0.6$ & $1.0 \pm 0.4$ & $0.5 \pm 0.3$ & $0.1 \pm 0.1$ & $0.6 \pm 0.3$ & $0.3 \pm 0.2$ \\
\hline $\begin{array}{c}\text { Fe ion irradiated to } \\
\text { 32 dpa }\end{array}$ & $10.5 \pm 1.4$ & $2.3 \pm 0.7$ & $1.4 \pm 0.6$ & $0.8 \pm 0.3$ & $0.1 \pm 0.1$ & $0.5 \pm 0.3$ & $0.4 \pm 0.3$ \\
\hline $\begin{array}{c}\text { Neutron irradiated to } \\
\text { 32 dpa }\end{array}$ & $11.9 \pm 1.2$ & $3.4 \pm 0.7$ & $1.6 \pm 0.4$ & $0.2 \pm 0.1$ & $0.01 \pm 0.02$ & $1.1 \pm 0.4$ & $0.5 \pm 0.3$ \\
\hline
\end{tabular}

Table IV. Average concentrations of chemical elements (at. \%) in matrix of the ODS Eurofer steel for different irradiation doses.

\begin{tabular}{|c|c|c|c|c|c|c|c|}
\hline at. \% & $\mathrm{Cr}$ & $\mathrm{Y}$ & $\mathrm{O}$ & $\mathrm{V}$ & $\mathrm{N}$ & $\mathrm{Mn}$ & $\mathrm{Si}$ \\
\hline $\begin{array}{c}\text { Unirradiated } \\
\text { state }\end{array}$ & $7.9 \pm 0.7$ & $0.03 \pm 0.01$ & $0.08 \pm 0.01$ & $0.11 \pm 0.02$ & $0.02 \pm 0.01$ & $0.31 \pm 0.04$ & $0.18 \pm 0.03$ \\
\hline $\begin{array}{c}\text { Fe ion irradi- } \\
\text { ated to 3 dpa }\end{array}$ & $9.2 \pm 0.3$ & $0.03 \pm 0.01$ & $0.11 \pm 0.01$ & $0.18 \pm 0.02$ & $0.015 \pm 0.003$ & $0.29 \pm 0.03$ & $0.26 \pm 0.02$ \\
\hline $\begin{array}{c}\text { Fe ion irradi- } \\
\text { ated to 10 dpa }\end{array}$ & $8.7 \pm 0.4$ & $0.05 \pm 0.01$ & $0.16 \pm 0.02$ & $0.18 \pm 0.03$ & $0.01 \pm 0.01$ & $0.36 \pm 0.03$ & $0.23 \pm 0.03$ \\
\hline $\begin{array}{c}\text { Fe ion irradi- } \\
\text { ated to 13 dpa }\end{array}$ & $8.3 \pm 0.3$ & $0.07 \pm 0.01$ & $0.15 \pm 0.01$ & $0.18 \pm 0.02$ & $0.010 \pm 0.004$ & $0.35 \pm 0.02$ & $0.22 \pm 0.01$ \\
\hline $\begin{array}{c}\text { Fe ion irradi- } \\
\text { ated to 32 dpa }\end{array}$ & $9.5 \pm 0.2$ & $0.09 \pm 0.01$ & $0.21 \pm 0.01$ & $0.25 \pm 0.04$ & $0.015 \pm 0.003$ & $0.40 \pm 0.02$ & $0.25 \pm 0.02$ \\
\hline $\begin{array}{c}\text { Neutron irradi- } \\
\text { ated to 32 dpa }\end{array}$ & $9.4 \pm 0.5$ & $0.12 \pm 0.01$ & $0.22 \pm 0.02$ & $0.21 \pm 0.03$ & $0.006 \pm 0.003$ & $0.37 \pm 0.02$ & $0.21 \pm 0.02$ \\
\hline
\end{tabular}

\section{DISCUSSION}

Contributions to hardening of different obstacle types in the frameworks of the Dispersed Barrier Hardening (DBH) model are in general considered by a root sum square rule [26] as described by $\Delta \sigma_{\text {tot }}=\sqrt{\sum_{i} \Delta \sigma_{i}^{2}}$, where $\Delta \sigma_{i}^{2}$ is the change due to the $i$-th short range obstacles as 
loops, voids, precipitates, etc. Hardening $\Delta \sigma_{i}$ caused by the interaction of moving dislocations with randomly distributed obstacles of type $i$ is $\Delta \sigma_{i}=M_{\mathrm{T}} \alpha_{\mathrm{i}} \mu b \sqrt{N_{\mathrm{i}} d_{\mathrm{i}}}$, where $\mu$ is the shear modulus of the matrix, $b$ is the Burgers vector of gliding dislocations, $\alpha_{i}$ is the barrier strength, $M_{\mathrm{T}}$ is the Taylor factor and $N_{i}, d_{i}$ are the number density and mean size of obstacles respectively.

TEM study of irradiated Eurofer 97 specimens irradiated at low temperatures $250-450{ }^{\circ} \mathrm{C}$ shows the formation of dislocation loops of various sizes in the range of 5 to $25 \mathrm{~nm}$. At the irradiation dose of $16.3 \mathrm{dpa}$, the number density of dislocations is $\sim 4 \times 10^{21} \mathrm{~m}^{-3}$ [13]. As the dose increases to $32 \mathrm{dpa}$, the size of the observed defects remains unchanged, but the density of the defects increases by an order of magnitude [14]. Quantitative TEM analysis of precipitation and grain boundary segregation in neutron irradiated Eurofer 97 to a dose of 32 dpa at 330-340 ${ }^{\circ} \mathrm{C}$ in the irradiation experiment ARBOR1 was carried out in [19].

In [14], hardening contributions of dislocation loops and voids were determined in Eurofer 97 after irradiation to $32 \mathrm{dpa}$ at $330{ }^{\circ} \mathrm{C}$ in ARBOR1: $\Delta \sigma_{\text {loops }}=355 \mathrm{MPa}$ and $\Delta \sigma_{\text {voids }}=$ $110 \mathrm{MPa}$. As shown in $[14,19]$, experimentally determined hardening $\left(\Delta \sigma_{\exp }=492 \mathrm{MPa}\right)$ which was observed after irradiation to 32 dpa could not be completely explained by the TEM-visible irradiation changes alone. As it was shown in [19], the contribution of further precipitation growth of $\mathrm{MX}$ and $\mathrm{M}_{23} \mathrm{C}_{6}$ induced by neutron irradiation can be neglected. Additionally, grain boundary segregation of chromium induced by neutron irradiation was investigated and detected in the irradiated specimens. The authors of [14] point to the possibility of the formation of $\alpha^{\prime}$ phase in neutron irradiated Eurofer97 steel.

As it was shown in our study, APT observed precipitates in neutron irradiated Eurofer 97 are not $\alpha^{\prime}$ phase. However, they may be nuclei of the $\alpha^{\prime}$ phases. The contribution to hardening from these precipitates $\Delta \sigma_{\alpha^{\prime} \text { nucl }}$ can be calculated in the frameworks of the DBH model, in which the barrier strength of the $\alpha^{\prime}$ phase nucleus $\alpha_{\alpha^{\prime} \text { nucl }}$ is fitted to the experimental results on hardening. In the case of $\alpha_{\alpha^{\prime} \text { nucl }}=5.2 \times 10^{-3}$, the contribution of $\alpha^{\prime}$ phase nuclei to hardening is $322 \mathrm{MPa}$, and the total irradiation induced hardening corresponds to the experimental value of $492 \mathrm{MPa}$. This $\alpha_{\alpha^{\prime} \text { nucl }}$ is a minimal value and does not contradict the barrier strength values known for $\alpha^{\prime}$ phase.

So, the precipitates revealed by APT make nearly the same contribution to hardening of Eurofer 97 as dislocation loops do. And if put together, the contributions from obstacles observed by TEM and APT are enough to explain the experimental hardening of Eurofer 97 after neutron irradiation to $32 \mathrm{dpa}$ at $330{ }^{\circ} \mathrm{C}$.

ODS steels hardening is caused by different obstacle types such as oxides, nanoclusters, dislocations and additional alloying elements. The increase in yield strength of ODS Eurofer due to oxide dispersed strengthening is about $500 \mathrm{MPa}$ at RT, and $330 \mathrm{MPa}$ at $550{ }^{\circ} \mathrm{C}$ [18]. Under irradiation, characteristics (size, number density) of these obstacles change, and some new obstacle types can also appear. Unfortunately, ODS Eurofer specimens irradiated in ARBOR projects were not studied by TEM. It was APT study that revealed considerable changes in nanoclusters in the neutron irradiated steel to $32 \mathrm{dpa}$ at $330^{\circ} \mathrm{C}$. In ODS Eurofer irradiated with heavy ions at low temperatures (RT, $300{ }^{\circ} \mathrm{C}$ and $400{ }^{\circ} \mathrm{C}$ ), dislocation loops were observed [23, 29]. TEM study also showed an increase in density of small $(<5 \mathrm{~nm})$ oxide particles [23]. The yield stress of ODS Eurofer under neutron irradiation at $300^{\circ} \mathrm{C}$ increases by $\sim 10 \%$ per 1 dpa up to a few dpa $[18,19]$, and after irradiation to 40 dpa it increases by $116 \%$ [9]. In our estimation, the contributions to hardening from nanoclusters and dislocation loops are comparable and can 
explain the total experimental hardening of ODS Eurofer irradiated in ARBOR 1 project. However, for a quantitative analysis it is necessary to obtain more detailed information about radiation induced dislocation loops and about the value of barrier strength of Y-O nanoclusters with various compositions. The evolution of matrix chemical composition should also be taken into account for calculation of total hardening under irradiation.

\section{CONCLUSIONS}

Eurofer 97 and ODS Eurofer RAFM steels exhibit significant radiation embrittlement under low temperature neutron irradiation. In this work, APT study of these steels irradiated with neutrons and heavy ions at low temperature was carried out. TEM studies revealed dislocation loops in the irradiated steels. At the same time, APT showed early stages of solid solution decomposition in Eurofer 97 . High density $\left(10^{24} \mathrm{~m}^{-3}\right)$ of $\sim 3-5 \mathrm{~nm}$ clusters enriched in chromium, manganese, and silicon atoms were found in Eurofer 97 irradiated in BOR-60 reactor to 32 dpa at $332^{\circ} \mathrm{C}$. In addition to that, in this steel, which was irradiated with Fe ions up to the dose of 24 dpa, the analysis of pair correlation functions calculated using APT data also showed the nucleation of Cr-enriched precipitates.

APT study of ODS Eurofer found a significant change in the nanocluster composition after neutron irradiation to $32 \mathrm{dpa}$ at $330^{\circ} \mathrm{C}$ and an increase in cluster number density. The study of the ODS steel irradiated with Fe ions at low temperatures found similar changes in nanoclusters. TEM also showed an increase in density of small $(<5 \mathrm{~nm})$ oxide particles.

Combined analysis of APT and TEM visible obstacles makes it possible to explain the total increase in hardening of these steels under irradiation. This analysis was completed in this work for Eurofer 97 irradiated to $32 \mathrm{dpa}$ at $330{ }^{\circ} \mathrm{C}$. However, for calculating the yield strength of ODS Eurofer, it is necessary to perform a quantitative analysis of dislocation structure and to determine the barrier strength of the clusters with various composition.

\section{REFERENCES}

1. R. Lindau, A. Möslang, M. Rieth, M. Klimiankou, E. Materna Morris, A. Alamo, F. Tavassoli, C. Cayron, M. Lancha, P. Fernandez, N. Baluc, R. Schaublin, E. Diegele, G. Filacchioni, J.W. Rensman, B.V.D. Schaaf , E. Lucon, and W. Dietz, Fusion Eng. Des. 75-79, 989-996 (2005). 2. R. Lindau, A. Möslang, M. Schirra, P. Schlossmacher, M. Klimenkov, J. Nucl. Mater. 307-311, 769 (2002).

3. Ch.Ch. Eiselt, M. Klimenkov, R. Lindau, A. Möslang, H.R.Z. Sandim, A.F. Padilha, D. Raabe, J. Nucl. Mater. 385, 231 (2009).

4. M. Klimiankou, R. Lindau, A. Möslang, J. Nucl. Mater. 329-333, 347-351 (2004).

5. A.A. Aleev, N.A. Iskandarov, M. Klimenkov, R. Lindau, A. Möslang, A.A. Nikitin, S.V. Rogozhkin, P. Vladimirov, and A.G. Zaluzhnyi, J. Nucl. Mater. 409, 65-71 (2011). 6. A.-A.F. Tavassoli, A. Alamo, L. Bedel, L. Forest, J.-M. Gentzbittel, J.-W. Rensman, E. Diegele, R. Lindau, M. Schirra, R. Schmitt, H.C. Schneider, C. Petersen, A.-M. Lancha, P. Fernandez, G. Filacchioni, M.F. Maday, K. Mergia, N. Boukos, Baluc, P. Spatig, E. Alves, E. Lucon, J. Nucl. Mater. 329-333, 257-262 (2004). 
7. B. van der Schaaf, F. Tavassoli, C. Fazio, E. Rigal, E. Diegele, R. Lindau, G. LeMarois, Fusion Eng. Des. 69, 197-203 (2003).

8. C. Petersen, A. Povstyanko, V. Prokhorov, A. Fedoseev, O. Makarov, and B. Dafferner, J. Nucl. Mater. 367-370, 544-549 (2007).

9. J. Henry, X. Averty, and A. Alamo, J. Nucl. Mater. 417, 99-103 (2011).

10. S.V. Rogozhkin, A.A. Aleev, A.G. Zaluzhnyi, A.A. Nikitin, N.A. Iskandarov, P. Vladimirov, R. Lindau, and A. Möslang, J. Nucl. Mater. 409, 94-99 (2011).

11. S.V. Rogozhkin, A.A. Nikitin, A.A. Aleev, A.B. Germanov, A.G. Zaluzhnyi, Inorg. Mater. Appl. Res. 4 (2), 112-118 (2013).

12. R. Coppola, R. Lindau, R.P. May, A. Möslang, and M. Valli, J. Nucl. Mater. 386-388, 195198 (2009).

13. E. Materna Morris, A. Möslang, R. Rolli, and H.C. Schneider, J. Nucl. Mater. 386-388, 422425 (2009).

14. E. Materna Morris, A. Möslang, R. Rolli, and H.C. Schneider, Fus. Eng. Des. 86, 2607-2610 (2011).

15. M. Klimenkov, E. Materna Morris, and A. Möslang, J. Nucl. Mater. 417, 124-126 (2011).

16. O.J. Weiß, E. Gaganidze and J. Aktaa, Quantative, Adv. Sci. Technol. (Faenza, Italy) 73, 118-123 (2010).

17. E. Gaganidze, C.Petersen, E. Materna Morris, C. Dethloff, O.J. Weiß, J. Aktaa, A.

Povstyanko, A. Fedoseev, O. Makarov, and V. Prokhorov, J. Nucl. Mater. 417, 93-98 (2011).

18. N. V. Luzginova, J. Rensman, P. Pierick, and J. B. J. Hegeman, J. Nucl. Mater. 428, 192-196 (2012).

19. D. A. McClintock, M. A. Sokolov, D. T. Hoelzer, and R. K. Nanstad, J. Nucl. Mater. 392, 353-359 (2009).

20. E. Lucon, A. Leenaers, and W. Vandermeulen, Fusion Eng. Des. 82, 2438-2443 (2007).

21. C. Dethloff , E. Gaganidze, J. Aktaa, J. Nucl. Mater. 454, 323-331 (2014).

22. S. V. Rogozhkin, N. N. Orlov, b, A. A. Aleev, A. G. Zaluzhnyi, M. A. Kozodaev,

R. P. Kuibida, T. V. Kulevoi, A. A. Nikitin, B. B. Chalykh, R. Lindau, A. Möslang, and P.

Vladimirov, Phys. Met. Metallogr. 116 (1), 72-78 (2015).

23. S. Rogozhkin, A. Bogachev, O. Korchuganova, A. Nikitin, N. Orlov, A. Aleev, A.

Zaluzhnyi, M.Kozodaev, T. Kulevoy, B. Chalykh, R. Lindau, A. Möslang, P. Vladimirov, M.

Klimenkov, M. Heilmaier, J. Wagner, S. Seils, J. Nucl. Mater. Energy (2016)

doi:10.1016/j.nme.2016.06.011

24. S. V. Rogozhkin, A. A. Aleev, A. G. Zaluzhnyi, R. P. Kuibeda, T. V. Kulevoy, A. A. Nikitin,

N. N. Orlov, B. B. Chalyh, V.B. Shishmarev, Phys. Met. Metallogr. 113 (2), 200-211 (2012).

25. G. Kropachev, R. Kuibeda, A. Kozlov, B. Chalyh, A.D. Fertman, T. Kulevoy, A. Nikitin, A.

Aleev, S. Rogozhkin, Rev. Sci. Instrum. 81 (1), $02 B 906$ (2010).

26. M.K. Miller, Atom Probe Tomography: Analysis at the Atomic Level, New York: Kluwer, (2000).

25. M. Klimenkov, R. Lindau, A. Möslang, J. Nucl. Mater. 386-388, 553-556 (2009).

26. G.E. Lucas, J. Nucl. Mater. 206, 287-305 (1993).

27. F. Danoix and P. Auger, Mater. Charact. 44,177-201 (2000).

28. S. V. Rogozhkin, O. A. Korchuganova, A. A. Aleev, Inorg. Mater. Appl. Res. 7 (2), 210-213 (2016).

29. D. Brimbal, L. Beck, O. Troeber, E. Gaganidze, P. Trocellier, J. Aktaa, R. Lindau, J. Nucl.

Mater. 465, 236-244 (2015). 